\title{
Group B streptococcal infection: when does vertical transmission take place?
}

\author{
C A Michie, R Blumberg
}

\begin{abstract}
Expression of CD45 isoforms was used to estimate when group B streptococci had infected a child born with low Apgar scores who subsequently died. The measure suggested that infection was present more than 24 hours before delivery, thus distinguishing perinatal infection as the primary event which preceded intrapartum asphyxia in this case.

(Arch Dis Child 1995; 73: F46-F47)
\end{abstract}

Keywords: group B streptococci, vertical transmission.

Group B streptococci are a significant cause of early onset sepsis in developed countries. ${ }^{1}$ It is not always clear when infection took place. We report a case in which use of activation markers on the surface of lymphocytes suggested that infection in utero had an important role in the infant's poor outcome.

\section{Case report}

A healthy 32 year old woman was delivered of her first child, a girl, by Ventouse assisted delivery for failure to progress in the second stage of labour. The pregnancy had been uneventful; labour had started with spontaneous rupture of membranes at 38 weeks' gestation, 21.5 hours before delivery. Fetal heart rate monitoring in the first stage of labour showed only mild and intermittent lack of variability. Scalp pH three hours before birth was $7 \cdot 32$. The mother was not feverish and had not received antibiotics.

At birth the infant was floppy, blue, and apnoeic with a heart rate of 60 beats per minute; the arterial cord $\mathrm{pH}$ was $7 \cdot 08$. Resuscitation required intubation and adrenaline via the endotracheal tube. Apgar scores were 3 at one minute, 2 at five minutes, and 3 at 10 minutes. The infant weighed $3.55 \mathrm{~kg}$. She was transferred, ventilated, to the neonatal

Dr Colin Michie.

Accepted 25 April 1995 intensive care unit; she remained unresponsive and hypotonic. The blood pressure at 30 minutes of life was $71 / 51 \mathrm{~mm} \mathrm{Hg}$, the serum glucose $4.2 \mathrm{mmol} / \mathrm{l}$, arterial $\mathrm{pH} 7 \cdot 11$ and the base deficit was $-22 \cdot 2 \mathrm{mmol} / \mathrm{l}$. Her electrolytes were in the normal range, the haemoglobin was $185 \mathrm{~g} / \mathrm{l}$, the corrected white cell count was $21.6 \times 10^{9} / 1$ (38\% neutrophils, these showing toxic vacuolation) and platelet count $223 \times 10^{9} / 1$. She was given broad spectrum antibiotics and restricted fluids. Generalised seizures noted at 2 hours of age were treated with phenobarbitone and diazepam. The blood pressure was stable, but she remained hypotonic with intermittent seizures despite correction of the acidosis. An ultrasound scan demonstrated a low Doppler pulsatility index in the middle cerebral arteries. Magnetic resonance imaging revealed cerebral oedema, and proton magnetic resonance spectroscopy a high lactate. On day 2 the corrected white cell count increased to $33.4 \times 10^{9} / 1$, with $57 \%$ neutrophils; the child remained in a deep coma with increasing limb tone, seizures, and fluctuations in temperature. Following discussion with the parents concerning the poor prognosis of severe hypoxic ischaemic encephalopathy, ventilatory support was withdrawn.

A blood culture taken on admission was positive for group B streptococcus, as were surface swabs, a high vaginal swab, and a placental culture from the mother. Post mortem examination showed bilateral bronchopneumonia and hypoxic ischaemic brain injury dating to the time of birth. The thymus showed signs of recent stress. Histological analysis of the placenta showed chorioamnionitis, intervillositis, and funisitis.

Dried blood films prepared from blood collected at 2 and 30 hours of life were single and double-stained with antibodies to CD3, CD56, and CD45R0 using a previously described method. ${ }^{2}$ As case controls, blood films were prepared from a heel prick from a term infant admitted for observation of her transient tachypnoea, and from a term infant who was delivered with severe intrapartum asphyxia following a massive placental bleed. A venous sample from a healthy adult was also examined using the same technique. Using a fluorescence microscope, more than 100 single-stained, and double-stained cells were counted (table).

\section{Discussion}

Apnoea was the initial feature of severe group B streptococcal infection in the delivery room. Blood films and the post mortem examinations suggested that sepsis was an important

*These figures represent the percentages of cells bearing the first marker which also express the second - that is, the proportions of CD 3 and CD56 positive cells, respectively, which express CD45R0; the remaining CD 3 or $C D 56$ positive cells express CD45RA. 
consideration before birth, but the absence of maternal fever and hypotension in the infant at the time of delivery seemed to mitigate against infection and supported intrapartum asphyxia as the cause of her illness. Increased expression of CD45R0 in the early blood sample supported the argument that the infant's immune system was stimulated for at least 24 hours before sampling, and that infection had been present in utero.

In vitro data from adult and cord lymphocytes and in vivo data in adults show that it takes 24-48 hours for the expression of CD45RA, the predominant isoform of CD45 (the leucocyte common antigen) to change to CD45R0 on the surface of $T$ cells. This period of activation seems to be shorter (eight to 12 hours) in natural killer cells. ${ }^{3}$ Expression of CD45R0 was found on over $15 \%$ of cord blood $\mathrm{T}$ cells in situations of infection in utero. ${ }^{4}$ Increased CD45R0 expression in this infant therefore suggested that infection had been active for at least 24 hours before sampling, although these are the first in vivo data reviewed in this age group.

Group B streptococci may invade the infant before, during, or following delivery. Antibiotic prophylaxis in the intrapartum period reduces mortality, ${ }^{5}$ but not all mothers exhibit signs of infection, as in this case. Such presentations lend support to the argument of maternal vaccination or prophylactic antibiotics. Host markers, such as CD45R0, may prove valuable in future in determining those factors which influence the rate and extent of infection.

1 Isaacs D, Moxon ER. Group B Streptococcus. In: Isaacs D, Moxon ER, eds. Neonatal Infections. Oxford: ButterworthHeinemann Ltd, 1991: 119-23.

2 Erber WN, Pinching AJ, Mason DY. Immunocytochemica detection of $\mathrm{T}$ and $\mathrm{B}$-cell populations in routine blood smears. Lancet 1984; i: 1042-6.

3 Braakman E, Sturm E, Vijverberg $K$, van Krimpen BA Gratama JW, Bolhuis RLH. Expression of CD45 isoforms by fresh and activated human $\gamma \delta \mathrm{T}$ lymphocytes and natural killer cells. Int Immunol 1991; 3: 691-6.

4 Michie CA, Harvey D. Can expression of CD45R0, a T-cell surface molecule, be used to detect congenital infection? Lancet 1994; 343: 1259-60.

5 Ohlsson A, Myhr TL. Intrapartum chemoprophylaxis of perinatal group B streptococcal infections: a critical review perinatal group B streptococcal infections: a critical review
of randomised controlled trials. Am $\mathcal{f}$ Obstet Gynecol 1994; 170: $910-7$ 